\title{
The role of inflammation and interleukin-I in acute cerebrovascular disease
}

This article was published in the following Dove Press journal:

Journal of Inflammation Research

19 August 2013

Number of times this article has been viewed

\section{James Galea' \\ David Brough ${ }^{2}$}

'Manchester Academic Health Sciences Center, Brain Injury Research Group, Clinical Sciences Building, Salford Royal Foundation Trust, Salford, UK; ${ }^{2}$ Faculty of Life Sciences, University of Manchester, AV Hill Building, Manchester, UK
Correspondence: David Brough Faculty of Life Sciences, University of Manchester, AV Hill Building, Oxford Road, Manchester, MI3 9PT, UK

Tel +44 I6I 2755039

Fax +44 I6I 2755948

Email david.brough@manchester.ac.uk
Abstract: Acute cerebrovascular disease can affect people at all stages of life, from neonates to the elderly, with devastating consequences. It is responsible for up to $10 \%$ of deaths worldwide, is a major cause of disability, and represents an area of real unmet clinical need. Acute cerebrovascular disease is multifactorial with many mechanisms contributing to a complex pathophysiology. One of the major processes worsening disease severity and outcome is inflammation. Pro-inflammatory cytokines of the interleukin (IL)-1 family are now known to drive damaging inflammatory processes in the brain. The aim of this review is to discuss the recent literature describing the role of IL-1 in acute cerebrovascular disease and to provide an update on our current understanding of the mechanisms of IL-1 production. We also discuss the recent literature where the effects of IL-1 have been targeted in animal models, thus reviewing potential future strategies that may limit the devastating effects of acute cerebrovascular disease.

Keywords: cerebral ischemia, stroke, inflammation, microglia, interleukin-1, caspase-1

\section{Acute cerebrovascular disease}

Acute cerebrovascular disease is a myriad of clinical conditions that can present in many different ways, from periventricular hemorrhage in preterm babies, through subarachnoid hemorrhage (SAH), ischemic and hemorrhagic stroke, and vascular dementia in middle and old age.

Evidence based treatments for acute stroke are limited to thrombolysis for up to $20 \%$ of all strokes, antiplatelet agents, and stroke unit care. There is some evidence for decompressive craniectomy in highly selected patients as a life saving measure, and ongoing trials are investigating the efficacy of endovascular interventions such as thrombectomy for acute ischemic stroke. For SAH, there is currently no treatment that addresses the ischemic injury occurring at ictus and the use of nimodipine still results in up to a third of patients developing delayed cerebral ischemia. In intracerebral hemorrhage (ICH), no current therapies other than those addressing hypertension at presentation improve the outcome, ${ }^{1}$ and surgical trials including the recent Surgical Trial in Lobar Intracerebral Haemorrhage (STICH II) study have also failed to show any benefit. ${ }^{2}$ It is therefore evident that treatment of acute cerebrovascular disease remains an area of unmet clinical need. While there have been numerous rodent studies targeting inflammation, particularly in stroke, only a few of these have successfully translated into clinical practice. Furthermore, there remains a paucity of research into the targeting of key molecular pathological mechanisms that underpin neurodegeneration occurring in all of these processes. The purpose of this review is to discuss the potential for targeting a pro-inflammatory cytokine called interleukin 
(IL)-1 and its regulatory processes as potential treatments for cerebrovascular disease.

\section{Inflammation}

Inflammation is an important host defense response to injury or infection. Key to an inflammatory response is the recruitment of polymorphonuclear cells to the site of injury or infection. This response is coordinated by cascades of cellular and molecular events that include the production of pro-inflammatory mediators such as cytokines, chemokines, and cell adhesion molecules. Many of the tools of the inflammatory response that target pathogens, such as proteases and reactive oxygen species, also kill healthy cells. This collateral damage may be acceptable when compared to the consequences of pathogen survival. However, when these responses occur in the absence of infection, during injury, or noncommunicable disease states, this collateral damage leads to a worsening of the condition and as such represents a therapeutic target. ${ }^{3}$ Inflammation in the context of injury, and in the absence of infection, is considered as sterile inflammation. Acute brain cerebrovascular disease results primarily from a disruption to blood flow to a region of the brain and thus the inflammation stimulated by such injuries can be considered sterile. Cytokines of the IL- 1 family, namely the IL- $1 \alpha$ and IL-1 $\beta$ isoforms, are strongly implicated in sterile inflammatory responses that worsen acute cerebrovascular disease. ${ }^{4}$

\section{IL-I production}

In a healthy brain, IL-1 is undetectable, but it is expressed after an injury or during disease. ${ }^{5}$ For example, in an animal model of stroke (induced by occlusion of the middle cerebral artery), a rapid increase in expression of both IL- $1 \alpha,{ }^{6}$ and IL-1 $\beta$ are observed in microglia within hours of the insult and within areas of the brain that experience cell death. ${ }^{7}$ Although IL- $1 \alpha$ and IL-1 $\beta$ appear to be produced mainly by microglia in this model, there is evidence that astrocytes may also express IL-1. ${ }^{7,8}$ Microglia expressing IL- $1 \alpha$ are also observed in regions adjacent to the bleed site in a rat model of SAH. ${ }^{9}$ Preclinical pharmacological or genetic manipulation studies have demonstrated a consistently detrimental effect of IL-1 in experimental stroke. ${ }^{10}$ In clinical studies, increased intrathecal concentrations of IL-1 $\beta$ are associated with increased injury, ${ }^{11}$ and with increased incidence of vasospasm following SAH. ${ }^{12}$ IL-1 induces release of the inflammatory mediator IL-6 from glia and neurons through type-1 receptor IL-1RI signaling. ${ }^{13,14}$ IL-6 concentrations are more readily detectable and tend to be more consistent over time. IL-6 is increased in cerebrovascular disease within the cerebrospinal fluid (CSF) and the brain extracellular fluid. In stroke, intrathecal IL-6 concentrations correlate with lesion size, ${ }^{11,15}$ while in SAH, increased intrathecal IL-6 concentrations are associated with demonstrable vasospasm. ${ }^{12}$

IL-1 expression is stimulated by molecular motifs expressed by pathogens termed pathogen associated molecular patterns, or by molecules released from dead or injured tissue/cells, or that are modified during disease called damage associated molecular patterns (DAMPs). DAMPs are endogenous molecules normally retained within cells and thus not exposed to immune surveillance. Upon their release during cell death, DAMPs are sensed by pattern recognition receptors (PRRs) on the membranes of cells of the innate immune system, such as microglia, resulting in signaling cascades that induce the expression of pro-inflammatory cytokines. ${ }^{16,17}$ The specific DAMPs that drive the expression of IL-1 after an acute brain injury are unknown, although there are many potential candidates identified from other disease states including high mobility group protein B1, heat shock proteins, heparin sulfate, and many other endogenous molecules released by dying cells. ${ }^{17}$ Acute phase proteins such as serum amyloid A may also induce expression of IL-1 in microglia after a brain injury after gaining access to the brain through a damaged blood-brain barrier. ${ }^{18}$ Many of the DAMPs discovered stimulate PRRs of the toll-like receptor (TLR) family, resulting in the activation of signaling pathways such as nuclear factor- $\kappa \mathrm{B}$ and p38 mitogen activated protein kinase that regulate the expression of multiple inflammatory genes in addition to $I L I A$ and $I L 1 B .{ }^{19}$ TLRs share a conserved toll- and IL-1 receptor related domain with IL-1RI, and thus TLRs and IL-1RI share many common signaling steps following stimulation. ${ }^{19,20}$

Many pro-inflammatory mediators have conventional secretory routes from the cell, but perhaps indicative of their position as master cytokines, IL- $1 \alpha$ and IL- $1 \beta$ are subject to an additional regulatory step. Stimulating cells to express IL-1 is often referred to as a priming step. A second stimulus is required to elicit their cellular release. ${ }^{21}$ Both IL-1 forms are initially produced as precursors that reside in the cytoplasm of the cell following the initial priming step. Pro-IL-1 $\beta$ is inactive at IL-1RI, and requires proteolytic cleavage to yield a mature, secreted, biologically active molecule. Pro-IL-1 $\alpha$ has some biological activity, which is strongly enhanced following proteolytic cleavage (Figure 1). ${ }^{22,23}$

\section{IL-I processing and secretion}

The protease most commonly reported to cleave pro-IL-1 $\beta$ is caspase-1. Caspase- 1 is also produced as an inactive 


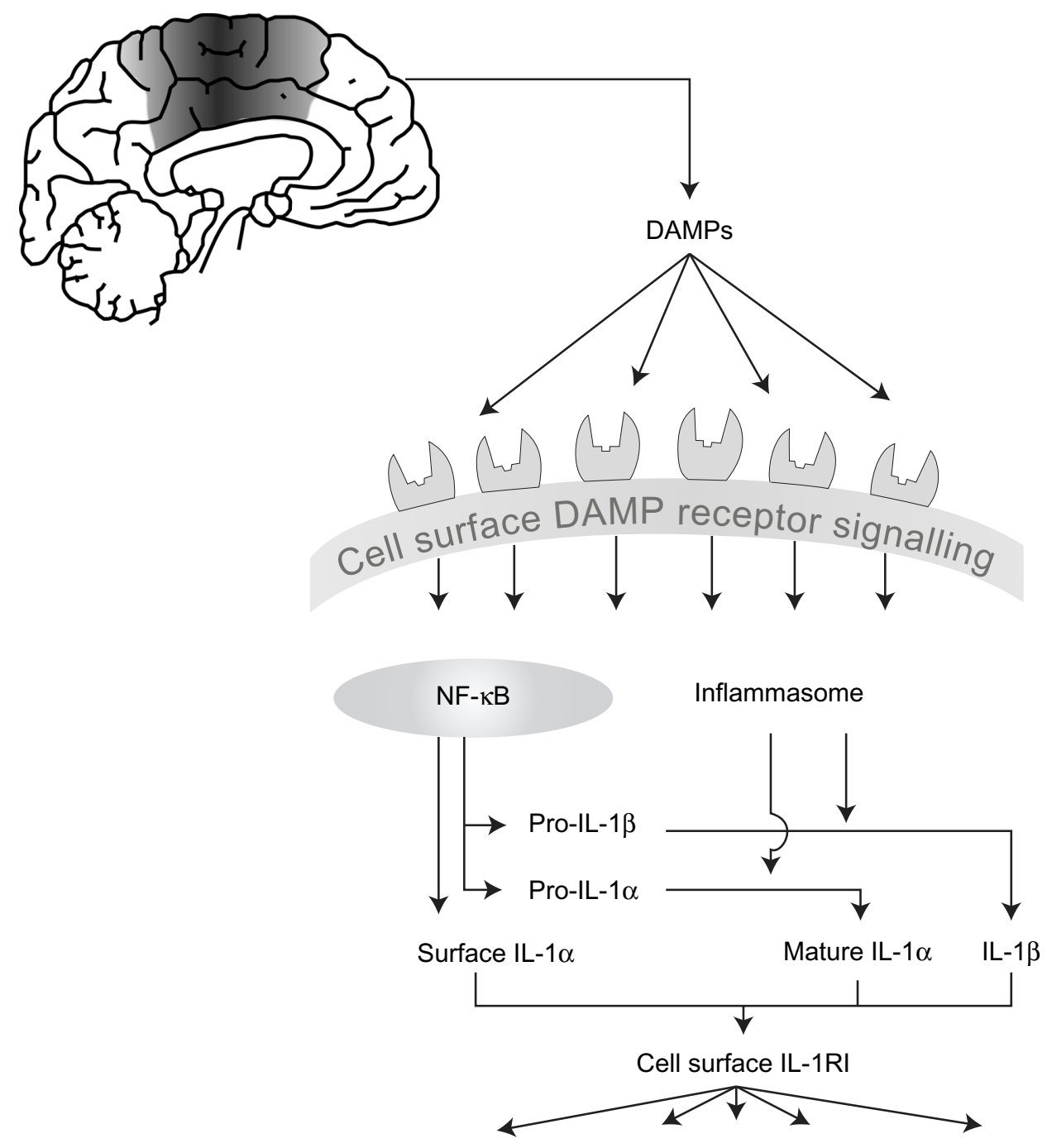

Figure I The development of inflammation in acute cerebrovascular disease.

Notes: Cell death as a result of acute cerebrovascular disease results in the generation of numerous damage associated molecular patterns (DAMPs) that act on pattern recognition receptors on immune cells to initiate and shape the inflammatory response. DAMPs stimulate "priming," resulting in increased expression of interleukin (IL)-I, and also stimulate inflammasome assembly, activation of caspase-I, and of other proteases capable of processing and activating IL-I. IL-I (both IL-I $\alpha$ and IL-I $\beta$ ) is released and can then stimulate the type I IL-I receptor on responsive cells to trigger inflammatory signaling pathways with pleiotropic effects.

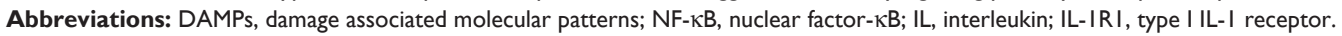

precursor however, and a "primed" cell must encounter a secondary stimulus that facilitates the activation of caspase- 1. The secondary stimulus that drives IL- $1 \beta$ processing and release during sterile disease is an additional DAMP. During sterile inflammation the secondary stimulus is typically sensed by a cytosolic PRR called NACHT, LRR and PYD domains-containing protein (NLRP) $3 .{ }^{24}$ Sterile activators of NLRP3 include (but not exclusively) molecules such as adenosine triphosphate (ATP), ${ }^{25}$ sphingosine, ${ }^{26}$ and monosodium urate. ${ }^{27}$ There is limited evidence supporting a direct interaction between DAMP and NLRP3 and additional host cellular signals such as $\mathrm{K}^{+}$efflux, ${ }^{28}$ lysosomal destabilization and cathepsin activity, ${ }^{29}$ and ROS production and/or mitochondrial dysfunction, ${ }^{30}$ are suggested to be important.
Once activated NLRP3 interacts via an interaction of pyrin domains with an adaptor protein called apoptosis-associated speck-like protein containing a caspase recruitment domain (ASC). ASC recruits pro-caspase-1 into the complex via an interaction of caspase activation and recruitment domain (CARD) that subsequently results in caspase-1 activation and processing of pro-IL-1 $\beta$. This multimolecular IL- $1 \beta$ processing complex is called the inflammasome. ${ }^{31}$ A role for the NLRP3 inflammasome in brain inflammation has been suggested using animal models of Alzheimer's disease and multiple sclerosis. ${ }^{32,33}$ However, there is as yet no evidence to support a role of NLRP3 in ischemic brain injury. Another inflammasome forming PRR that is found in the brain is NLRP $1,{ }^{34}$ which is expressed by neurons. ${ }^{35}$ NLRP1 has 
a CARD and can thus interact with caspase- 1 directly, ${ }^{36}$ although the presence of ASC does appear to enhance its activity. ${ }^{37}$ The NLRP1 inflammasome is suggested to be important in rodent models of acute CNS injury through studies using neutralizing antibodies in models of spinal cord injury and traumatic brain injury in the rat, ${ }^{38,39}$ and in a mouse model of thromboembolic stroke. ${ }^{40}$

Once processed, IL- $1 \beta$ is secreted rapidly from the cell into the extracellular environment where it stimulates signaling pathways on IL-1RI expressing cells. The precise mechanisms of IL- $1 \beta$ secretion are poorly understood. IL- $1 \beta$ does not follow the conventional endoplasmic reticulumgolgi pathway of secretion and harnesses one or more of the nonconventional secretory routes. We have recently reviewed the literature for mechanisms of IL-1 $\beta$ secretion and postulated that the mechanism involved may depend on the strength of the inflammatory stimulus. ${ }^{21}$ Based on this simple theory we classified IL- $1 \beta$ secretion mechanisms as (1) rescue and redirect where IL-1 $\beta$ targeted for degradation via lysosomal or autophagic routes could be rescued and secreted; (2) protected release where IL-1 $\beta$ is contained in secreted vesicles such as microvesicles shed from the plasma membrane, or exosomes released by the exocytosis of multivesicular bodies; and (3) terminal release where IL- $1 \beta$ is secreted through pores in the plasma membrane, with these pores ultimately resulting in an osmotic lysis of the cell. Whilst the vast majority of the literature reporting IL-1 $\beta$ release focuses on the inflammasome, it is important to note that additional caspase- 1 independent mechanisms exist, and of particular relevance to sterile disease may be extracellular processing of pro-IL-1 $\beta$ by neutrophil derived proteases including proteinase $3 .^{41,42}$ An extracellular cathepsin $\mathrm{D}$ dependent processing of pro-IL-1 $\beta$ has also been reported to occur from microglia stimulated with ATP under acidic conditions. ${ }^{43}$

In contrast to IL-1 $\beta$, there has been comparatively little research into the mechanisms of IL- $1 \alpha$ processing and secretion. The secretion of IL- $1 \alpha$ in response to DAMP stimulation is also reported to depend upon the inflammasome. ${ }^{44}$ Pro-IL- $1 \alpha$ is not a substrate for caspase- 1 and it is not clear how inflammasome activation regulates its processing and release, although a non-catalytic role of caspase- 1 and calpain protease dependent processing are implicated. ${ }^{44,45}$ An alternative $^{23}$ to this model was proposed recently where pro-IL- $1 \alpha$ binds tightly to an intracellular form of the type II IL-1 receptor (IL-1RII). Upon activation of the inflammasome, IL-1RII is cleaved by caspase- 1 rendering pro-IL- $1 \alpha$ available for calpain mediated cleavage. ${ }^{23}$ Granzyme B is also reported to cleave pro-IL-1 $\alpha$ leading to an increase in its biological activity. ${ }^{22}$ In contrast to IL-1 $\beta$, pro-IL- $1 \alpha$ can traffic to the nucleus of the expressing cell and this mechanism may limit IL- $1 \alpha$ release during cell death. ${ }^{46}$

\section{Consequences of IL-I signaling}

IL-1 released by microglia into the extracellular space can act directly on nearby neurons. IL- $1 \beta$ stimulates the activation of Src tyrosine kinases in neurons which results in phosphorylation of the NR2A and NR2B N-methyl-D-aspartate (NMDA) receptor subunits. ${ }^{47}$ This subsequently results in increased calcium flux after NMDA receptor activation and increased excitotoxic cell death. ${ }^{47}$ IL-1 $\beta$ can also exert neurotoxic effects via glial cell dependent production of reactive oxygen and proteases. ${ }^{48,49}$ In a microglia-neuron coculture model, aggregated amyloid- $\beta$ (pathological feature of Alzheimer's disease) induced neurotoxicity was lost when caspase-1 knockout microglia were used instead of wildtype. ${ }^{50}$ Thus, "local" effects of IL-1 dependent signaling could contribute to brain injury.

We now know that in addition to centrally produced IL-1, peripheral sources also contribute to brain inflammation after experimental stroke. ${ }^{51}$ Systemic IL-1 $\beta$ exacerbates neuronal injury after experimental stroke by increasing the production and infiltration of neutrophils into the ischemic tissue. ${ }^{52}$ This neutrophil dependent toxicity is at least in part dependent upon a matrix metalloproteinase induced disruption of the blood-brain barrier. ${ }^{53}$ In a culture system, platelet derived IL- $1 \alpha$ can activate brain endothelial cells to produce chemokines and increase expression of adhesion molecules, thus facilitating the transmigration of neutrophils across an endothelial cell layer. ${ }^{54}$ Transmigrated neutrophils were recently shown to be neurotoxic via a mechanism dependent upon proteases associated with neutrophil extracellular traps. ${ }^{55}$ Thus, multiple sources and effects of IL-1 may contribute to the inflammation dependent damage that occurs during acute cerebrovascular disease.

Another consequence of IL-1 dependent inflammation in acute cerebrovascular disease is immune depression, which contributes to a susceptibility to infection. ${ }^{56,57}$ This is of particular clinical relevance, where infections following ischemic stroke ${ }^{58,59}$ and $\mathrm{SAH}^{60}$ are observed with increased frequency, and are a major cause of morbidity in those surviving the initial insult. This phase of immune depression represents an unbalanced peripheral anti-inflammatory reaction following the initial insult, ${ }^{56,61}$ and results in altered 
lymphocyte function ${ }^{62}$ and depletion, ${ }^{63}$ reduced natural killer cell function, ${ }^{64}$ and a shift from Th1 to Th2 cytokine response. ${ }^{65}$ The two main mechanisms that are thought to cause immune depression after an acute brain injury are (1) stimulation of the hypothalamic-pituitary-adrenal axis releasing adrenal cortisol, and (2) catecholamine mediated IL-10 release. ${ }^{57,66} \mathrm{IL}-1 \beta$ and IL-6 are direct inducers of both mechanisms. ${ }^{56,67}$ Our research group has also demonstrated the central role of IL-1 in poststroke immune depression by inducing its reversal with the IL-1 receptor antagonist (IL-1Ra). ${ }^{68}$ Further studies are currently underway in SAH and $\mathrm{ICH}$. In $\mathrm{ICH}$, although a reduction in white blood cells is not usually observed, ${ }^{69}$ there is clinical evidence that plasma IL-10 concentrations are raised which may contribute to immune depression and increased risk of infection. ${ }^{70}$

\section{Targeting inflammation in acute cerebrovascular disease}

A variety of pharmacological interventions against the IL-1 system have been studied in experimental models of acute cerebrovascular disease where they have been shown to limit neuronal injury. ${ }^{71}$ We have recently reviewed these in more depth elsewhere, ${ }^{71}$ but briefly, they range from biologicals such as IL-1Ra and neutralizing IL-1 $\beta$ antibodies, to small molecule inhibitors of inflammatory signaling pathways and caspase- $1 .^{71}$ Although protective effects observed when targeting nuclear factor- $\kappa \mathrm{B}$ or $\mathrm{p} 38$ mitogen activated protein kinase could be ascribed to a plethora of inflammatory signaling processes, at least comparable neuroprotective effects are observed with agents that specifically target the IL-1 pathway. Caspase-1 inhibitors are highly protective in rodent models of acute cerebrovascular disease. ${ }^{72-74}$ Antibodies that target IL- $1 \beta$ directly, ${ }^{75}$ or components of the NLRP1 inflammasome are also protective in experimental models. ${ }^{39,40}$ For many years, IL-1Ra has been known to offer significant neuroprotection in experimental models of brain injury. ${ }^{5}$ These studies have recently been extended to animals with comorbidities commonly seen in stroke patients, where similar neuroprotective effects of IL-1Ra are also reported. ${ }^{76}$ Clinically, IL-1Ra has also been administered to patients with ischemic and hemorrhagic stroke where it was effective in reducing peripheral markers of inflammation. ${ }^{77}$ In patients with SAH, IL-1Ra has been administered through both intravenous $^{78}$ and subcutaneous routes (Galea, unpublished data, 2012). Intravenous IL-1Ra has been demonstrated to penetrate CSF and achieve concentrations that are associated with neuroprotection in rodent studies. ${ }^{79}$ Together these data suggest that targeting the IL-1 system could represent a real opportunity for treating acute cerebrovascular disease.

\section{Conclusions, open questions, and future perspectives}

In summary, there is compelling evidence to suggest that effective targeting of the IL-1 system could be therapeutic in the treatment of acute cerebrovascular disease. Despite the large number of potential DAMPs and signaling pathways involved in the regulation of IL-1, its actions depend entirely on IL-1RI activation, which is the only known signaling receptor for IL- $1 \alpha$ and IL-1 $\beta$ (Figure 1). Perhaps that is why IL-1Ra has proven to be so effective and is showing the greatest promise currently. Importantly IL-1 Ra is also protective in comorbid models of stroke in rodents which better reflect the human condition. ${ }^{76}$

In addition to nonrepresentative animal models, there are other reasons for the persistent failure of drugs that require an appreciation of the underlying biological pathways. Changes in the activity of single enzymes normally have only small effects on pathway fluxes, and multisite modulation is necessary to effect large changes in fluxes. ${ }^{80}$ Targeting multiple nodes in a signaling network may therefore be a more effective therapeutic strategy. ${ }^{81}$ The potential of this approach has already been demonstrated in a number of cellular models, including our own work on the expression of IL-1 $\beta .{ }^{82}$ The existence of such dynamic interactions and changes within the inflammatory cascade may thus be overcome by approaches that target multiple points within the inflammatory cascade.

At the fundamental level there exist a number of questions. Many arise from our yet incomplete understanding of inflammasome priming and activation and assembly, and the mechanism of secretion for IL-1. More specifically, the mechanisms and inflammasomes regulating IL-1 in acute brain injury remain unknown. Relative contributions of IL-1 $\alpha$ and IL-1 $\beta$ to the expanding infarct or developing ischemia are also unknown. Understanding these processes will likely lead to the identification of new therapeutic targets that may further direct strategies to target the inflammation that occurs during acute cerebrovascular disease.

\section{Acknowledgments}

We are grateful to Professors Nancy Rothwell and Pippa Tyrrell, and to Dr Emmanuel Pinteaux (all from the University of Manchester), for providing detailed feedback on a draft version of this manuscript. 


\section{Disclosure}

The authors report no conflicts of interest in this work.

\section{References}

1. Keep RF, Hua Y, Xi G. Intracerebral haemorrhage: mechanisms of injury and therapeutic targets. Lancet Neurol. 2012;11:720-731.

2. Mendelow AD, Gregson BA, Rowan EN, Murray GD, Gholkar A, Mitchell PM; for the STICH II Investigators. Early surgery versus initial conservative treatment in patients with spontaneous supratentorial lobar intracerebral haematomas (STICH II): a randomised trial. Lancet. Epub May 29, 2013.

3. Rock KL, Latz E, Ontiveros F, Kono H. The sterile inflammatory response. Anпu Rev Immunol. 2010;28:321-342.

4. Lucas SM, Rothwell NJ, Gibson RM. The role of inflammation in CNS injury and disease. Br J Pharmacol. 2006;147(Suppl 1):S232-S240.

5. Allan SM, Tyrrell PJ, Rothwell NJ. Interleukin-1 and neuronal injury. Nat Rev Immunol. 2005;5:629-640.

6. Luheshi NM, Kovacs KJ, Lopez-Castejon G, Brough D, Denes A. Interleukin-1alpha expression precedes IL-1beta after ischemic brain injury and is localised to areas of focal neuronal loss and penumbral tissues. J Neuroinflammation. 2011;8:186.

7. Amantea D, Bagetta G, Tassorelli C, Mercuri NB, Corasaniti MT. Identification of distinct cellular pools of interleukin-1 beta during the evolution of the neuroinflammatory response induced by transient middle cerebral artery occlusion in the brain of rat. Brain Res. 2010;1313:259-269.

8. Denes A, Ferenczi S, Halasz J, Kornyei Z, Kovacs KJ. Role of CX3CR1 (fractalkine receptor) in brain damage and inflammation induced by focal cerebral ischemia in mouse. J Cereb Blood Flow Metab. 2008;28: $1707-1721$.

9. Greenhalgh AD, Brough D, Robinson EM, Girard S, Rothwell NJ, Allan SM. Interleukin-1 receptor antagonist is beneficial after subarachnoid haemorrhage in rat by blocking haem-driven inflammatory pathology. Dis Model Mech. 2012;5:823-833.

10. Lambertsen KL, Biber K, Finsen B. Inflammatory cytokines in experimental and human stroke. J Cereb Blood Flow Metab. 2012;32: $1677-1698$

11. Tarkowski E, Rosengren L, Blomstrand C, et al. Early intrathecal production of interleukin-6 predicts the size of brain lesion in stroke. Stroke. 1995;26:1393-1398.

12. Hendryk S, Jarzab B, Josko J. Increase of the IL-1 beta and IL-6 levels in CSF in patients with vasospasm following aneurysmal SAH. Neuro Endocrinol Lett. 2004;25:141-147.

13. Lee SC, Liu W, Dickson DW, Brosnan CF, Berman JW. Cytokine production by human fetal microglia and astrocytes. Differential induction by lipopolysaccharide and IL-1 beta. J Immunol. 1993;150: 2659-2667.

14. Ringheim GE, Burgher KL, Heroux JA. Interleukin-6 mRNA expression by cortical neurons in culture: evidence for neuronal sources of interleukin-6 production in the brain. J Neuroimmunol. 1995;63: 113-123.

15. Tarkowski E, Rosengren L, Blomstrand C, et al. Intrathecal release of pro- and anti-inflammatory cytokines during stroke. Clin Exp Immunol. 1997;110:492-499.

16. Chen GY, Nunez G. Sterile inflammation: sensing and reacting to damage. Nat Rev Immunol. 2010;10:826-837.

17. Piccinini AM, Midwood KS. DAMPening inflammation by modulating TLR signalling. Mediators Inflamm. 2010; Article ID 672395.

18. Savage CD, Lopez-Castejon G, Denes A, Brough D. NLRP3inflammasome activating DAMPs stimulate an inflammatory response in glia in the absence of priming which contributes to brain inflammation after injury. Front Immunol. 2012;3:288.

19. Newton K, Dixit VM. Signaling in innate immunity and inflammation. Cold Spring Harb Perspect Biol. 2012;4:1-19.

20. Weber A, Wasiliew P, Kracht M. Interleukin-1 (IL-1) pathway. Sci Signal. 2010;19;3(105):cm1.
21. Lopez-Castejon G, Brough D. Understanding the mechanism of IL-1beta secretion. Cytokine Growth Factor Rev. 2011;22:189-195.

22. Afonina IS, Tynan GA, Logue SE, et al. Granzyme B-dependent proteolysis acts as a switch to enhance the proinflammatory activity of IL-1alpha. Mol Cell. 2011;44:265-278.

23. Zheng Y, Humphry M, Maguire JJ, Bennett MR, Clarke MC. Intracellular interleukin-1 receptor 2 binding prevents cleavage and activity of interleukin-1alpha, controlling necrosis-induced sterile inflammation. Immunity. 2013;38:285-295.

24. Cassel SL, Sutterwala FS. Sterile inflammatory responses mediated by the NLRP3 inflammasome. Eur J Immunol. 2010;40:607-611.

25. Mariathasan S, Weiss DS, Newton K, et al. Cryopyrin activates the inflammasome in response to toxins and ATP. Nature. 2006;440: 228-232.

26. Luheshi NM, Giles JA, Lopez-Castejon G, Brough D. Sphingosine regulates the NLRP3-inflammasome and IL-1beta release from macrophages. Eur J Immunol. 2012;42:716-725.

27. Martinon F, Petrilli V, Mayor A, Tardivel A, Tschopp J. Gout-associated uric acid crystals activate the NALP3 inflammasome. Nature. 2006; 440:237-241.

28. Petrilli V, Papin S, Dostert C, Mayor A, Martinon F, Tschopp J. Activation of the NALP3 inflammasome is triggered by low intracellular potassium concentration. Cell Death Differ. 2007;14: $1583-1589$.

29. Hornung V, Latz E. Critical functions of priming and lysosomal damage for NLRP3 activation. Eur J Immunol. 2010;40:620-623.

30. Shimada K, Crother TR, Karlin J, et al. Oxidized mitochondrial DNA activates the NLRP3 inflammasome during apoptosis. Immunity. 2012;36:401-414.

31. Strowig T, Henao-Mejia J, Elinav E, Flavell R. Inflammasomes in health and disease. Nature. 2012;481:278-286.

32. Heneka MT, Kummer MP, Stutz A, et al. NLRP3 is activated in Alzheimer's disease and contributes to pathology in APP/PS1 mice. Nature. 2013;493:674-678.

33. Jha S, Srivastava SY, Brickey WJ, et al. The inflammasome sensor, NLRP3, regulates CNS inflammation and demyelination via caspase-1 and interleukin-18. J Neurosci. 2010;30:15811-15820.

34. Yin Y, Yan Y, Jiang X, et al. Inflammasomes are differentially expressed in cardiovascular and other tissues. Int J Immunopathol Pharmacol. 2009;22:311-322.

35. Kummer JA, Broekhuizen R, Everett H, et al. Inflammasome components NALP 1 and 3 show distinct but separate expression profiles in human tissues suggesting a site-specific role in the inflammatory response. J Histochem Cytochem. 2007;55:443-452.

36. Schroder K, Tschopp J. The inflammasomes. Cell. 2010;140:821-832.

37. Faustin B, Lartigue L, Bruey JM, et al. Reconstituted NALP1 inflammasome reveals two-step mechanism of caspase-1 activation. Mol Cell. 2007;25:713-724

38. de Rivero Vaccari JP, Lotocki G, Marcillo AE, Dietrich WD, Keane RW. A molecular platform in neurons regulates inflammation after spinal cord injury. J Neurosci. 2008;28:3404-3414.

39. de Rivero Vaccari JP, Lotocki G, Alonso OF, Bramlett HM, Dietrich WD, Keane RW. Therapeutic neutralization of the NLRP1 inflammasome reduces the innate immune response and improves histopathology after traumatic brain injury. J Cereb Blood Flow Metab. 2009;29:1251-1261

40. Abulafia DP, de Rivero Vaccari JP, Lozano JD, Lotocki G, Keane RW, Dietrich WD. Inhibition of the inflammasome complex reduces the inflammatory response after thromboembolic stroke in mice. $J$ Cereb Blood Flow Metab. 2009;29:534-544.

41. Fantuzzi G, Ku G, Harding MW, et al. Response to local inflammation of IL-1 beta-converting enzyme-deficient mice. J Immunol. 1997;158: $1818-1824$.

42. Joosten LA, Netea MG, Fantuzzi G, et al. Inflammatory arthritis in caspase 1 gene-deficient mice: contribution of proteinase 3 to caspase 1-independent production of bioactive interleukin-1beta. Arthritis Rheum. 2009;60:3651-3662. 
43. Takenouchi T, Iwamaru Y, Sugama S, et al. The activation of P2X7 receptor induces cathepsin D-dependent production of a $20-\mathrm{kDa}$ form of IL-1beta under acidic extracellular $\mathrm{pH}$ in LPS-primed microglial cells. J Neurochem. 2011;117:712-723.

44. Gross O, Yazdi AS, Thomas CJ, et al. Inflammasome activators induce interleukin-1alpha secretion via distinct pathways with differential requirement for the protease function of caspase-1. Immunity. 2012;36: 388-400.

45. Luheshi NM, Rothwell NJ, Brough D. Dual functionality of interleukin-1 family cytokines: implications for anti-interleukin-1 therapy. Br J Pharmacol. 2009;157:1318-1329.

46. Luheshi NM, McColl BW, Brough D. Nuclear retention of IL-1 alpha by necrotic cells: a mechanism to dampen sterile inflammation. Eur J Immunol. 2009;39:2973-2980.

47. Viviani B, Bartesaghi S, Gardoni F, et al. Interleukin-1beta enhances NMDA receptor-mediated intracellular calcium increase through activation of the Src family of kinases. J Neurosci. 2003;23:8692-8700.

48. Thornton P, Pinteaux E, Gibson RM, Allan SM, Rothwell NJ. Interleukin-1-induced neurotoxicity is mediated by glia and requires caspase activation and free radical release. J Neurochem. 2006;98: 258-266.

49. Thornton P, Pinteaux E, Allan SM, Rothwell NJ. Matrix metalloproteinase-9 and urokinase plasminogen activator mediate interleukin-1induced neurotoxicity. Mol Cell Neurosci. 2008;37:135-142.

50. Halle A, Hornung V, Petzold GC, et al. The NALP3 inflammasome is involved in the innate immune response to amyloid-beta. Nat Immunol. 2008;9:857-865

51. Denes A, Wilkinson F, Bigger B, Chu M, Rothwell NJ, Allan SM. Central and haematopoietic interleukin-1 both contribute to ischaemic brain injury in mice. Dis Model Mech. 2013;6:1043-1048.

52. McColl BW, Rothwell NJ, Allan SM. Systemic inflammatory stimulus potentiates the acute phase and $\mathrm{CXC}$ chemokine responses to experimental stroke and exacerbates brain damage via interleukin-1and neutrophil-dependent mechanisms. J Neurosci. 2007;27: 4403-4412.

53. McColl BW, Rothwell NJ, Allan SM. Systemic inflammation alters the kinetics of cerebrovascular tight junction disruption after experimental stroke in mice. J Neurosci. 2008;28:9451-9462.

54. Thornton P, McColl BW, Greenhalgh A, Denes A, Allan SM, Rothwell NJ. Platelet interleukin-1 \{alpha\} drives cerebrovascular inflammation. Blood. 2010;115:3632-3639.

55. Allen C, Thornton P, Denes A, et al. Neutrophil cerebrovascular transmigration triggers rapid neurotoxicity through release of proteases associated with decondensed DNA. J Immunol. 2012;189:381-392.

56. Meisel C, Schwab JM, Prass K, Meisel A, Dirnagl U. Central nervous system injury-induced immune deficiency syndrome. Nat Rev Neurosci. 2005;6:775-786

57. Woiciechowsky C, Schoning B, Lanksch WR, Volk HD, Docke WD. Mechanisms of brain-mediated systemic anti-inflammatory syndrome causing immunodepression. J Mol Med (Berl). 1999;77:769-780.

58. Weimar C, Roth MP, Zillessen G, et al. Complications following acute ischemic stroke. Eur Neurol. 2002;48:133-140.

59. Grabska K, Gromadzka G, Czlonkowska A. Infections and ischemic stroke outcome. Neurol Res Int. 2011;2011:691348.

60. Stevens RD, Nyquist PA. The systemic implications of aneurysmal subarachnoid hemorrhage. J Neurol Sci. 2007;261:143-156.

61. Iadecola C, Anrather J. The immunology of stroke: from mechanisms to translation. Nat Med. 2011;17:796-808

62. Weiss JM, Quan N, Sundar SK. Widespread activation and consequences of interleukin-1 in the brain. Ann NY Acad Sci. 1994;741:338-357.
63. Offner H, Vandenbark AA, Hurn PD. Effect of experimental stroke on peripheral immunity: CNS ischemia induces profound immunosuppression. Neuroscience. 2009;158:1098-1111.

64. Sundar SK, Becker KJ, Cierpial MA, et al. Intracerebroventricular infusion of interleukin 1 rapidly decreases peripheral cellular immune responses. Proc Natl Acad Sci U S A. 1989;86:6398-6402.

65. Catania A, Lonati C, Sordi A, Gatti S. Detrimental consequences of brain injury on peripheral cells. Brain Behav Immun. 2009;23:877-884.

66. Chamorro A, Amaro S, Vargas M, et al. Catecholamines, infection, and death in acute ischemic stroke. J Neurol Sci. 2007;252:29-35.

67. Bethin KE, Vogt SK, Muglia LJ. Interleukin-6 is an essential, corticotropin-releasing hormone-independent stimulator of the adrenal axis during immune system activation. Proc Natl Acad Sci U S A. 2000;97:9317-9322.

68. Smith CJ, Emsley HC, Udeh CT, et al. Interleukin-1 receptor antagonist reverses stroke-associated peripheral immune suppression. Cytokine. 2012;58:384-389.

69. Agnihotri S, Czap A, Staff I, Fortunato G, McCullough LD. Peripheral leukocyte counts and outcomes after intracerebral hemorrhage. J Neuroinflammation. 2011;8:160.

70. Dziedzic T, Bartus S, Klimkowicz A, Motyl M, Slowik A, Szczudlik A. Intracerebral hemorrhage triggers interleukin-6 and interleukin-10 release in blood. Stroke. 2002;33:2334-2335.

71. Brough D, Tyrrell PJ, Allan SM. Regulation of interleukin-1 in acute brain injury. Trends Pharmacol Sci. 2011;32:617-622.

72. Ross J, Brough D, Gibson RM, Loddick SA, Rothwell NJ. A selective, non-peptide caspase-1 inhibitor, VRT-018858, markedly reduces brain damage induced by transient ischemia in the rat. Neuropharmacology. 2007;53:638-642.

73. Suzuki H, Sozen T, Hasegawa Y, Chen W, Zhang JH. Caspase-1 inhibitor prevents neurogenic pulmonary edema after subarachnoid hemorrhage in mice. Stroke. 2009;40:3872-3875.

74. Wu B, Ma Q, Khatibi N, et al. Ac-YVAD-CMK decreases blood-brain barrier degradation by inhibiting caspase-1 activation of interleukinlbeta in intracerebral hemorrhage mouse model. Transl Stroke Res. 2010;1:57-64.

75. Yamasaki Y, Matsuura N, Shozuhara H, Onodera H, Itoyama Y, Kogure K. Interleukin-1 as a pathogenetic mediator of ischemic brain damage in rats. Stroke. 1995;26:676-680; discussion 681.

76. Pradillo JM, Denes A, Greenhalgh AD, et al. Delayed administration of interleukin-1 receptor antagonist reduces ischemic brain damage and inflammation in comorbid rats. J Cereb Blood Flow Metab. 2012;32: 1810-1819.

77. Emsley HC, Smith CJ, Georgiou RF, et al. A randomised phase II study of interleukin-1 receptor antagonist in acute stroke patients. J Neurol Neurosurg Psychiatry. 2005;76:1366-1372.

78. Clark SR, McMahon CJ, Gueorguieva I, et al. Interleukin-1 receptor antagonist penetrates human brain at experimentally therapeutic concentrations. J Cereb Blood Flow Metab. 2008;28:387-394.

79. Gueorguieva I, Clark SR, McMahon CJ, et al. Pharmacokinetic modelling of interleukin-1 receptor antagonist in plasma and cerebrospinal fluid of patients following subarachnoid haemorrhage. Br J Clin Pharmacol. 2008;65:317-325.

80. Thomas S, Fell DA. The role of multiple enzyme activation in metabolic flux control. Adv Enzyme Regul. 1998;38:65-85.

81. Hopkins AL. Network pharmacology: the next paradigm in drug discovery. Nat Chem Biol. 2008;4:682-690.

82. Small BG, McColl BW, Allmendinger R, et al. Efficient discovery of anti-inflammatory small-molecule combinations using evolutionary computing. Nat Chem Biol. 2011;7:902-908. 
Journal of Inflammation Research

Dovepress

\section{Publish your work in this journal}

The Journal of Inflammation Research is an international, peer-reviewed open-access journal that welcomes laboratory and clinical findings on the molecular basis, cell biology and pharmacology of inflammation including original research, reviews, symposium reports, hypothesis formation and commentaries on: acute/chronic inflammation; mediators of inflamma-

tion; cellular processes; molecular mechanisms; pharmacology and novel anti-inflammatory drugs; clinical conditions involving inflammation. The manuscript management system is completely online and includes a very quick and fair peer-review system. Visit http://www.dovepress.com/ testimonials.php to read real quotes from published authors.

Submit your manuscript here: http://www.dovepress.com/journal-of-inflammation-research-journal 